\title{
DEVELOPING A CONCEPTUAL MODEL OF FACTORS AFFECTING SOCIAL MEDIA NETWORKING USAGE IN E-LEARNING AT TALAL ABU GHAZALEH UNIVERSITY COLLEGE OF BUSINESS (TAGUCB) IN BAHRAIN
}

\author{
Mohammed Albarghouthi \\ Talal Abu-Ghazaleh University College of Business,College of Business Administration,Logistics \\ Department,Manama,Kingdom of Bahrain. \\ malbarghouthi@tagucb.edu.bh
}

\begin{abstract}
Social networking has become pervasive in all sectors in the $21^{\text {st }}$ century. The Kingdom of Bahrain is experiencing a big wave in reference to the use of social media networking in the context of a classroom. Indisputably, an innovative learning environment will be provided if this technology is astutely used. Within the e-learning environment, the technology acceptance model (TAM) has been heavily used to examine the acceptance of different types of technologies. As such, this study aims at discussing the main factors that affect usage of social media networking in e-learning by students and educators at the Talal Abu-Ghazaleh University College of Business (TAGUCB). Based on TAM, a proposed conceptual model of social media usage in e-learning is developed
\end{abstract}

\section{Indexing terms/Keywords}

Social Media, Technology Acceptance Model,E-learning.

\section{Academic Discipline And Sub-Disciplines}

Education; E-learning.

\section{INTRODUCTION}

The last couple of years have witnessed an immense growth in internet content that is essentially user generated through online tools often defined as social media[1].Social networking sites have increasingly become part of people's everyday life and subsequently builds social platforms that enable computer mediated communication[2]. The definition of social networking sites is broad and still evolving over time. However, they can be defined as web based services that allow users to create personal profiles that can be viewed by the general public or a limited connection known to the individual. This allows the users to build a list of friends or connections with whom they share a connection, view their friends list of networks as well as others based in organizations of interest to them. Ideally, the networks formed are not only complex but also varies in context as well as the sites utilized [3].

Consequently, the usage of the varied social networking sites have been linked to dissimilar resolves such as Facebook for the general social connection with friends, Linkedln for professional networks, Twitter for micro blogging, Instagram for sharing of photos and videos as well as the video sharing sites such as YouTube and Flicker. By and large the aforementioned sites have identical services to the users however they are differentiated by their distinct method of communication. In the academic circles, the impact of social media in global events such as the Arab Spring has aroused on going studies. Moreover, social media has the power to shape public opinion besides alter the course of history as was evidenced during the Arab Spring [4]. Unfortunately, this breeds suppressed fear of probable negative publicity in the novel media. There have been several studies $[5,6,7]$ focusing on impacts of social media on social, economic and academic aspects.

Generally, the majority of the social media users are students especially those in institutions of higher learning. Subsequently, the frequency of use of certain social media sites is varies. Researchers agree that the question of using information communication technology (ICT) is quite complex. Brown and Adler[8] argued that e-learninghas heightened the call for integration of social media tools such as podcasts, Facebook, Wikis and blogs in the teaching and learning process. The learners link the utilization of such social media tools in the learning process to benefits such as new knowledge creation. Ultimately, learning in this context takes place through engaging in conversations as well as collaborations on certain identified topics of study. Online learning has been stimulated through social networking that allows learners to constructively discuss about numerous topics. Nonetheless, this is as a form of learning has only been integrated in certain parts of the work. In reference to Bahrain, this novel form of learning has not yet been implemented. This is because the utilization of technology is prohibited in the classroom environment. Additionally, the utilization of technology by traditional educators is seldom when communicating to their students and colleagues. This is despite the fact that on a daily basis the majority of their students spend numerous hours in social networking sites such as Facebook and twitter. However, on the surface this looks like a waste of time and students' brainpower. Nevertheless, there is need for a critical look at the latent power of social networking technology [9].

In a quest to aid educators to develop online courses for students, TAGUCB is utilizing a Moodle-based e-learning management system. Although this is a step in the right direction, the e-learning platform lacks a provision for users to also link up through social sites such as Facebook due to cultural as well as safety reasons. Essentially, tapping into the limitless possibilities of social networking sites has the potential to heighten collaboration, which would in turn translate to

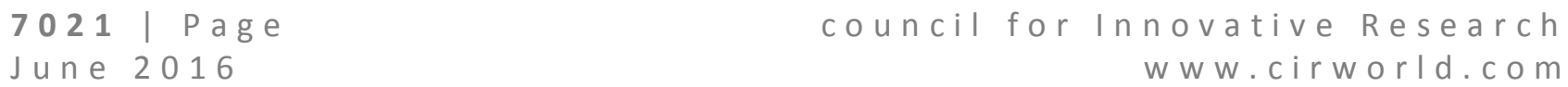


good students results. In a bid to adequately implement social networking in e-learning, TAGUCB educators as well as students required to continuously use it as well as integrate assessment and testing tools in the e-learning context. Subsequently, the use should be scaled up to the aspects of testing and assessment for purposes of full integration. In reference to this research study, it proposed a conceptual model by discussing the factors that may affect the usage of social networking in e-learning at TAGUCB.

\section{INFORMATION TECHNOLOGY ADOPTION MODELS}

There are several researchers in the IT community that have considered investigating the adoption of technology [10,11]. The most common models that have been developed to explain acceptance of IT systems include: Fishbein and Ajzen's [12] theory of reasoned action (TRA), Ajzen's[13[ theory of planned behavior (TPB) , Rogers' [14]innovation diffusion theory (IDT), Davis'[15] technology acceptance model (TAM), and Venkatesh and Davis'[16] theoretical extension of TAM referred to as TAM2.

\subsection{Technology Acceptance Model (TAM)}

Davis et al. [17] came up with TAMwhich over time has become the most broadly utilized and prominent models particularly in the fields of technology, information systems and services. The theory is drawn from theory of reasoned action (TRA) [12]. TRA was customized for the purpose of modelling user acceptance when it comes to the use of information technology. The main basis of TRA is that it begins from a premise of attitudes progresses to intentions and subsequently to behavior. Perceived usefulness (PU) and perceived easeof use (PEU)are the two major factors posited by TAM. Consequently, the two factors have an essential role when it comes to persuading behaviors' associated with IT acceptance. Davis et al.[17] defined perceived usefulness as the extent which an individual accepts as true that using a specific system will improve job performance. Subsequently, perceived ease of use is defined as the extent to which an individual trusts that using a specific system does not require much effort. Generally, PEU is postulated to be a predictor of $\mathrm{PU}$ otherwise referred to as user's appeal to using a system. Moreover, the two beliefs are also affected by other external variables. For example, in the extension of TAM Venkatesh and Davis'[16] added subjective normthat besides being linked to social influence is also a determinant to intention and perceived usefulness. Davis et al.[17]reckoned that many studies have illustrated that equally good is the explanatory power model that lacks the mediating aspect of attitude.

Technology acceptance model (TAM) is regarded being among the renowned models allied to technology acceptance and engagement, since it had portrayed immense potential in elaborating and envisaging information technology's user behavior $[18,19,20]$. Compared with other technology acceptance models, TAM has been highly recommended by different researchers [21, 16, and 22] to be highly powerful, predictive and parsimonious. However, the central constructs of the TAM do not adequately reveal the particular influences of technology as well as its utilization in context factorsthat have the potential to modify the users' acceptance [23].This is despite the fact that many information system researchers have examined and replicated the TAM and settled that it is a valid tool in predicting people's acceptance to the varied types of technology. According toMathieson[24]" without external factors TAM provides very general information on users' opinions about a system but does not yield "specific information that can better guide system development" (p. 173).

In light of the above, Davis [15] recommended that future research studies focusing on technology acceptance need to address other variables that influence ease of use, usefulness as well as user acceptance. Nonetheless, researchers cautioned that factors affecting the acceptances of different types of information technologies dependent on other aspects such as context, technology and target users [23]. To this end, this study will discuss the factors that may affect students' usage of social media in e-learning at TAGUCB.

\section{FACTORS AFFECTING THE USAGE OF SOCAIL MEDIA IN E-LEARNING ENVIRONMENT.}

An extensive amount of research has been undertaken by numerous authors in the factors that affect the adoption of information technology in different business sectors. However, there is no general unanimity regarding the precise factors that may affect the adoption of information technologies. This has been supported by Chung et al.[25] who reckoned that while different studies seem to overlap with each other in terms of the factors that affect the adoption of ERP systems, there is no general consensus regarding the factors that are absolutely imperative to the success of all ERP projects. Each company has to reflect on the precise combination of success factors that best suits its particular organizational circumstances. Different Researchers attempt to extend the TAM model with new variables and examine their influence on PEOU and PU in order to recognize boundary conditions. For instance,Agarwaland Prasad,[26] used five individual factors (e.g. training, prior experiences, , job position, level of education, and role with regard to technology) as external factors of PEOU and PU. Igbaria et al,[27] used three organizational factors (e.g. training, top management support and computer support) as external factors for PEOU and PU. Moreover, other researcher grouped the antecedents of PEOU and PU into different sets of variables. For instance, Schwarz [28] created three sets of groups including individual variables (e.g. computer experience, self-efficacy, prior experiences), organizational influences (e.g. management and external support, perceived resources) and technology characteristics (e.g. accessibility of the medium and interface type). Venkatesh and Davis [16] developed a model of the determinants of PU, which include PEOU, subjective norm, quality, image, job relevance etc. Venkatesh [29] proposed a model by identifying other determinants (e.g. self-efficacy, computer anxiety) of PEOU. Others like Venkatesh and Bala [30] merged the model proposed by (Venkatesh, [29] with TAM2 (Venkatesh and Davis [16] to propose a new model called TAM3.

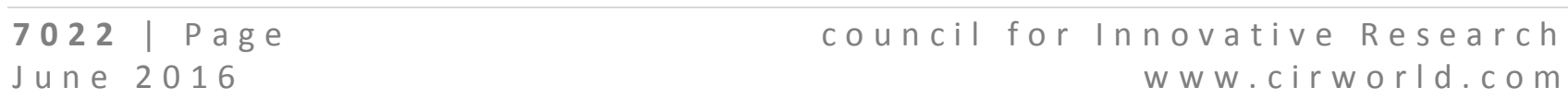


For the purpose of this research, two main categories of variables have been studied and shown to be relevant to understanding technology acceptance, especially in developing countries context like the Kingdom of Bahrain. The first category is construed as human factors and information literacy (computer self-efficacy, computer experience and computer playfulness). The second category is institutional factors (subjective norm and top management support).

\subsection{Human Factors and Information Literacy (HFIL)}

\subsubsection{Computer Playfulness (CP)}

Different research studies indicate that user entertainment has a considerable effect on the acceptance of certain type of technology. The adoption of a specific type of technology depends on the degree of playfulness perceived by the user of such technology. The more playfulness the users perceive by using the technology the more likely the adoption level will increase for that technology [31].

Moreover, according to [32, 33] there is a strong relationship between the utilization level of information systems and users perceived playfulness. In terms of social media networking, different researches $(34 ; 35,36,37)$ show that playfulness has a strong influence on intention to use a certain technologies (e.g. blogs. hedonic systems). In addition, both playfulness and usefulness have a great effect on the intention to use technology [38].

\subsubsection{Computer Experience (CE).}

Drawing from previous studies, there are a positive relationship between experience and computing technology. Similarly, a multiplicity of outcome such as effect towards computers has a positive relationship with computer usage [39]. Prior studies have suggested that a person's experience with a specific type of technology affect PEU and PU of the technology. Moreover, a learner success in a distance mode of learning is highly dependent on the users' knowledge on internet navigation, computer experience and ability to cope with applicable subject matter.

\subsubsection{Computer Self-Efficacy (CSE)}

Perceived efficacy arises from accomplishing certain performance targets, verbal persuasion, exceptional experience, and state of mind. Self-efficacy has been a critical pillar in social learning theory [40]. Venkatesh and Davis [41] and Venkatesh [29] explored the effect of self-efficacy on perceived ease of use in email and Gopher. Their studies revealed that perceptions regarding a new system's ease of use were dependent on an individual's computer self-efficacy. Furthermore, Lim [42] inferred that self-efficacy is a primary predictor of intention and subsequent behavior.

\subsection{Institutional Factors (IFs)}

\subsubsection{SUBJECTIVE NORM (SN)}

According to Fishbein and Ajzen [12] subjective norm is defined as an individual's perception towards what other people close to her/his think that she/he should or should not do when it comes to a specified behavior. Consequently, the term "subjective norm" can be identified as the social pressures put on an individual have or not to have an inclination to a certain behaviour [39].Ajzen [13] determined that subjective norm has a direct impact in the prediction of an individual's intention to utilize a computer. Accordingly, Venkataesh and Davis [16] identified that subjective norm has an indirect impact in the prediction of a person's intention to use a certain piece of technology. The acceptance of intention can be influenced by cultural values that directly impact on internal beliefs as precursors. Subjective norm in this particular study will be an external variable. It is anticipated that in regard to social networking in e-learning a positive influence will be drawn.

\subsubsection{Top Management Support (TMS)}

There are several studies [44, 45, 46, 47] that have tried to find out the impact of support from top management in regard to a specific technology or IT system. Zmud [48] noted that support from top management was a significant determinant of users' attitudes towards technology. According to Purvis et al [49] top management support influences individuals' perceive usefulness of the technology.

\subsection{Factors of Technology Acceptance Model}

\subsubsection{PerceivedUsefulness (PU)}

(Davis, [15], p. 320) defined Perceived usefulness as "the degree to which a person believes that using a particular system would enhance his or her job performance". Others [17] defined Perceived usefulness as "the prospective user's subjective probability that using a specific application system will increase his or her job performance within an organization" (p. 985). In another words, Perceived usefulness can be defined as the perceived benefits that stem from using a particular system. Venkatesh et al. [50] noted the variable has expansively been used in research studies and hence the agreement on its effect on behavioral intention.

\subsubsection{Perceived Ease Of Use (PEOU)}

Davis defined perceive ease of use as "the degree to which a person believes that using a particular system would be free of effort" (Davis, [15], p. 320). According to Davis,et al, [17] perceived ease of use is "the degree to which the prospective user expects the target system to be free of effort" (p. 985) in another words, perceive ease of use is the extent to which
7023 | P a g e
council for Innovative Research
June 2016
w w w. cir world. com 
an individual trusts that the utilization of a certain type of technology would be "free of effort". Several research studies on the subject provide evidence that perceive ease of use substantially influences the intention to use through its direct or indirect effects on PU[51,52]

\subsubsection{Behavioral Intention To Use (BI)}

This refers to the intention an individual has on utilizing a certain arrangement. It is implicit to note that both the conventional and extended versions of TAM acknowledge that the variable of intention to use is the only variable that has an influence on actual usage. Venkatesh and Davis [16] articulated that the role of intention as a predictor of usage is essential and is well supported in existent literature.

\section{PROPOSED MODEL}

Based on the previous discussion, PEOU has a positive effect on PU towards the usage of social media in e-learning, while PU has a positive effect on intention to use the technology. The intention to use is positively influence by perceived usefulness and perceived ease of use, while usage is positively influence by the intention to use. Both perceived ease of use and perceived usefulness fully mediates the relationships between the two groups of the external factors (human factors and information literacy and institutional factors) and behavioural intentions.

\section{Proposed Model}

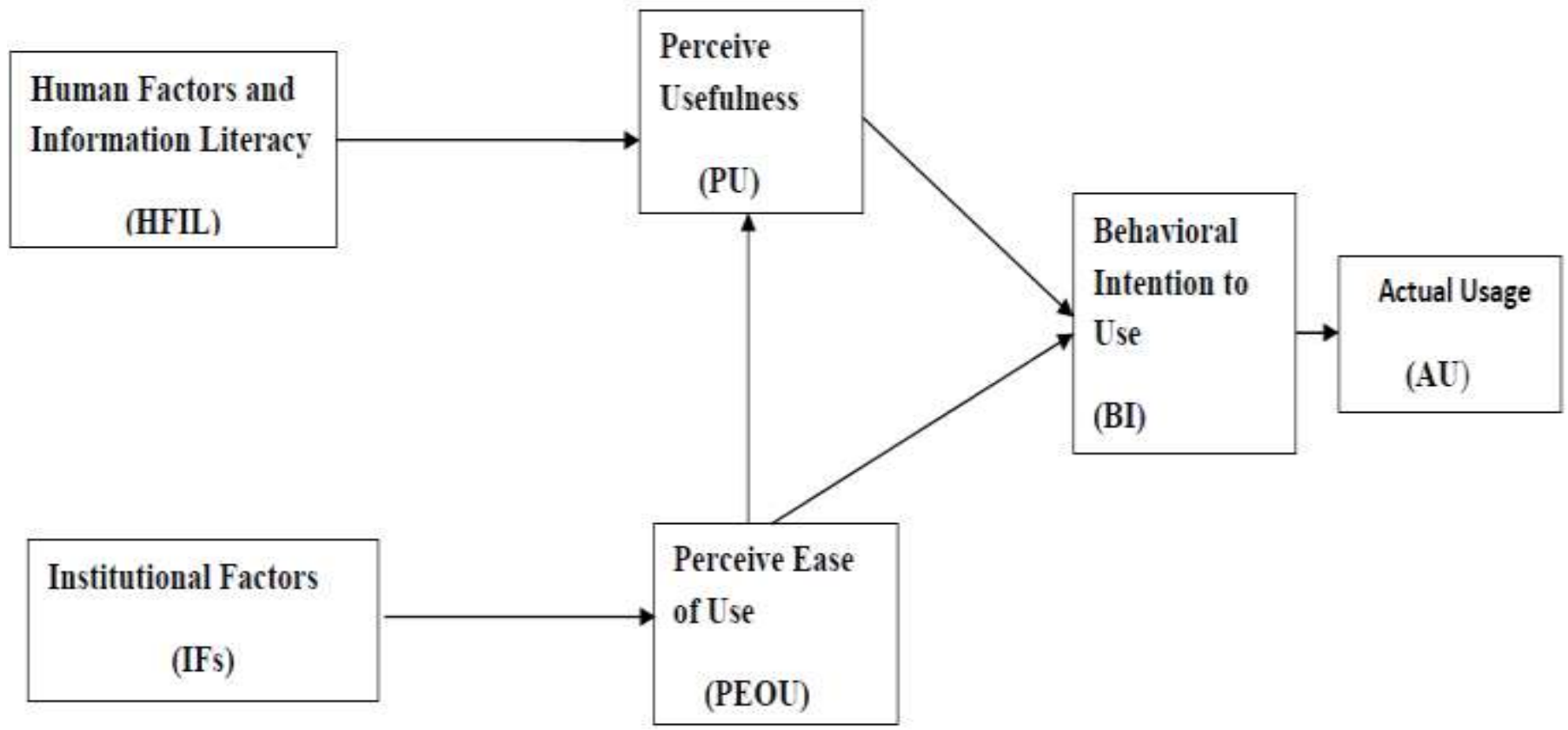

Fig 1: PROPOSED MODEL

\section{SUMMARY}

Online learning has been stimulated through social networking that allows learners to constructively discuss about numerous topics. Nonetheless, this is as a form of learning that has only been integrated in certain parts of e-learning. In reference to Bahrain, this novel form of learning has not yet been implemented. This is because the utilization of technology is delimitated in the classroom environment. This study aims at discussing the main factors that affect usage of social media networking in e-learning by students and educators at the Talal Abu-Ghazaleh University College of Business (TAGUCB). Davis et al. [17] came up with TAMwhich over time has become the most broadly utilized and prominent models particularly in the fields of technology, information systems and services. According to Mathieson[24] " without external factors TAM provides very general information on users' opinions about a system but does not yield "specific information that can better guide system development" (p. 173). However, there is no general unanimity regarding the precise factors that may affect the adoption of information technologies. For the purpose of this research, two main categories of variables have been studied and shown to be relevant to understanding technology acceptance, especially in developing countries context like the Kingdom of Bahrain. The first category is construed as human factors and information literacy (computer self-efficacy, computer experience and computer playfulness). The second category is institutional factors (subjective norm, top management support). Research indicates that both categories have an influence upon technology acceptance. The above proposed research model can be utilized in further study to measure the validity of the model in explaining social media adoption in in e-learning systems. 


\section{REFERENCES}

[1] Lopez, P, Bulchand-Gidumal, Gutierrez-Tano, J \& Diaz-Armas, R. 2011. Intentions to use social media in organizing and taking vacation trips, Computers in Human Behavior, vol. 27, pp. 640-654.

[2] Lin, Y \& Lu ,P 2011. Why people use social networking sites: An empirical study integrating network externalities and motivation theory, Computers in Human Behavior, vol. 27, pp. 1152-1161.

[3] Boyd, D. \& Ellison, N. 2007. Social Network Sites: Definition, History, and Scholarship, Journal of Computer-Mediated Communication, vol. 13, no. 1.

[4]Sahoo, S,2012. 'Social challenge for firms in UAE', The National, accessed 12/12/2012.

[5]Dana,B and Nicole,E. ,2007. "Social Network Sites: Definition, History, and Scholarship." Journal of Computer-Mediated Communication, $13(1)$.

[6] Ellison. B., Steinfield. C., and Lampe., C.2007. The benefits of Facebook "Friends:"social capital and college students' use of online social network sites. Journal of Computer-Mediated Communication 12 (2007) 1143-1168

[7] Hewitt, A. and Forte, A. 2006. Crossing boundaries: Identity management and student/faculty relationships on the Facebook.CSCW'06, November 4-8, Alberta, Canada

[8]Brown,S\& Adler, P 2008, Minds on Fire: Open Education, the Long Tail, and Learning 2.0, Educause review, pp. 1632.

[9]Klopfer, E. Osterweil, S. Groff,J. \&Haas,J. 2009. The instructional power of digital games, social networking, simulations, and how the teacher can leverage them, The Education Arcade

[10]Grandon, E. E. and Pearson, M. J. 2004 'Factors that differentiate between adopters and non-adopters of ecommerce: An empirical study of small and medium sized businesses' usefulness.' In proceedings of the Tenth Americans Conference on Information Systems. Atlanta, GA: Association for Information Systems

[11] Valier, F. M., McCarthy, R. V., Aronson, J. E. and O'Neill, H.,2004. 'The province of diffsion of innovation: Usable social theory for information system research.' In proceedings of the Tenth Americans Conference on Information Systems, Atlanta, GA: Association for Information Systems.

[12]Fishbein,M and Ajzen,I, 1975 Belief, attitude, intention, and behavior: An introduction to theory and research, MA: Addison-Wesley.

[13]Ajzen, I. 1985, From intention to actions: A theory of planned behavior. New York: Springer Verlag

[14] Rogers, E.M. 1983 Diffusion of Innovations. 3rded, New York, Free Press

[15] Davis, F. 1986. A Technology Acceptance Model for Empiricaly Testing New End-User Information Systems: Theory and Results, MIT Sloan School of Management

[16]Venkatesh, V. \& Davis, F. 2000, A theoretical extension of the technology acceptance model: four longitudinal field studies. Management Science 46, (2) 186-204.

[17] Davis, F.D., Bagozzi, R.P. \&Warshaw, P.R. 1989. User acceptance of computer technology: a comparison of two theoretical models.' Management Science 35, (8) 982-1003.

[18]Etsebeth, E. (2012). Trialability, perceived risk and complexity of understanding as determinants of cloud computing services adoption. Unpublished MBA dissertation, University of Pretoria, Pretoria, South Africa

[19]Surendran, P. (2012). Technology acceptance model: A survey of literature. International Journal of Business and Social Research, 2, 175-178.

[20]Tome, L., Johnston K.A., Meadows, A., \&Nyemba-Mudenda, M. (2014). Barriers to open source ERP adoption in South Africa. The African Journal of Information Systems, 6, 26-47.

[21]Ma, Q. and Liu, L. (2004) 'The technology acceptance model: a meta-analysis of empirical findings.' Journal of End User Computing 16, (1) 59-72.

[22] Lu, Y. B., Zhou, T. and Wang, B. (2009). Exploring Chinese users' acceptance of instant messaging using the theory of planned behavior, the technology acceptance model, and the flow theory. Computers in Human Behavior, 25 (1), 29-39.

[23] Moon, J. \& Kim, Y. 2001, Extending the TAM for a World Wide Web Context. Information and Management 38, (4) 217-231.

[24] Mathieson, K., 1991, 'Predicting user intentions: Comparing the technology acceptance model with theory of planned behavior'. Information Systems Research, 2(3), 173

[25]Chung, S.H. and Lee, D.H. (2005), "Impacts of TQM activities on employee's satisfaction in the support of task process, and on business performance in medical service industry", The Korea Service Management Society, Vol. 6 No. 1 pp. 57-85

$\begin{array}{lrl}7025 \text { I Page } & \text { councilfor Innovative Research } \\ \text { June } 2016 & \text { www.cirworld.com }\end{array}$


[26]Agarwal, B. \& Prasad, J. 1999, Are individual differences germane to the acceptance of new information technologies? Decision Sciences, vol. 30, no. 2, pp. 361-391.

[27]lgbaria, M., J. livari, and H. Maragahh (1995b) "Why do Individuals Use Computer Technology? A

Finnish Case Study" Information \& Management 29(5), pp. 227-238.

[28] Schwarz A (2003) Defining information technology acceptance: a human-centered, management-oriented perspective. PhD Thesis, University of Houston-University Park, USA.

[29]Venkatesh, V., and F.D. Davis (2000) "A Theoretical Extension of the Technology Acceptance Model: Four Longitudinal Field Studies" Management Science 46(2), pp. 186-204.

[30]Venkatesh, V., Bala, H., 2008. Technology acceptance model 3 and a research agenda on interventions, Decision Sciences, 39(2), 273-315.

[31] Davis, F.D., R.P. Bagozzi, and P.R. Warshaw (1992) "Extrinsic and Intrinsic Motivation to Use

Computers in the Workplace" Journal of Applied Social Psychology 22(14), pp.1111-1132.

[32] Kim, B., Choi, M., \& Han, I.2009. User behaviors toward mobile data services: The role of perceived fee and prior experienmce. Export Systems with Applications, 36(4), 8528-8536.

[33] Kim, B., \& Han, I. 2009. The role of trust belief in community-driven knowledge and its antecedents.Journal of the American Society for Information Science \& Technology, 60(5), 1012-1026

[34] Wang, Y., Lin, H., \& Liao, Y., 2010. Investigating the individual difference antecedents of perceived enjoyment in the acceptance of blogging.World Academy of Science, Engineering and Technology, 67, 1014-1023.

[35] Hsu, C.L., \& Lin, J.C. 2008. Acceptance of blog usage: The roles of technology acceptance, social influence and knowledge sharing motivation. Information \& Management, 45(1), 65-74.

[36] Lin, C.P., \&Bhattacherjee, A. (2010). Extending technology usage models to interactive hedonic technologies: A theoretical model and empirical test. Information Systems Journal, 20(2), 163-181.

[37] Van der Heijden, H. ,2004 User acceptance of hedonic information systems. MIS Quarterly, 28(4), 695-704.

[38]Levin,T. and Gordon, T. (1989) "Effect of gender and computer experience on attitudes towards," vol. 5, no. 1.

[39] Bandura, A. 1997 'Self-efficacy: toward a unifying theory of behavioral change.' Psychological Review 82, (2) 191215.

[40]Venkatesh, V., and F.D. Davis (1994) "Modeling the Determinants of Perceived Ease of Use"

Proceedings of the 15th International Conference on Information Systems, pp. 213-227.

[41] Lim, C. K. 2000 Computer self-efficacy, academic self-concept and other factors as predictors of satisfaction and future participation of adult learners in Web-based distance education. Dissertation Abstracts International, 61, 02A. (UMI No. 9962612).

[42] Taylor, S. \& Todd, P.A. 1995, Understanding information technology usage: a test of competing models. Information Systems Research 6, (2) 144-176

[43]Rivard, S., \& Huff, S. 1988. Factors of success for end-user computing.Communications of the ACM, 31(5), 552-561

[44] Kaiser, K., \&Srinivasan, A. 1982. User-analyst differences: An empirical investigation of attitudes related to systems development. Academy of Management Journal, 25(3), 630-646.

[45]Rockart, J., \& Flannery, L. 1983. The management of end-user computing.Communications of the ACM, 26(10), 776784.

[46]Premkumar, G., \& Ramamurthy, K. 1995. The role of organizational and interorganizational factors on decision mode for adoption of interorganizational systems. Decision Sciences, 26(3), 303-336

[47]Zmud, R. W. ,1979. Individual differences and MIS success: A review of the empirical literature. Management Science, 25(1), 966-979.

[48] Purvis, R. L., Sambamurthy, V. and Zmud, R. W. 2001. The Assimilation of Knowledge Platforms in Organizations: An Empirical Investigation. Organization Science, 12(2), 117-135.

[49]Venkatesh, V., Morris, M. G., Davis, F. D. \& Davis, G. B. 2000, Why don't men ever stop to ask for directions? Gender, social influence and their role in technology acceptance and usage behavior, MIS Quarterly, vol. 24, no. 1, pp. 115-139

[50]Venkatesh, V.,1999, Creation of favorable user perceptions: Exploring the role of intrinsic motivation, MIS Quarterly, vol. 23, no. 2, pp. 239-260

\section{P a g e}

Jun e 2016 council for Innovative Research w w w. cirworld. com 


\section{Author' biography with Photo}

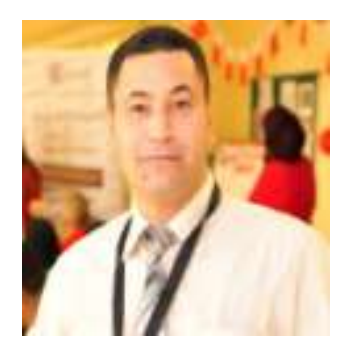

Mr. Mohammed Al-Barghouthi joined TAGUCB in 2013 after nearly two years of service to Laureate International Universities (Riyadh Polytechnic Institution). At RPI he has developed a unique academic curriculum for Logistics and Supply Chain Management program. He has published several research papers and articles in international conferences as well as international journals. Mr. Al-Barghouthi has 8 years of industrial experience within the logistics and supply chain networks. He has applied this combination of practical and academic experience to a variety of consultancies for corporations in different industrial fields.

\section{Education:}

-PhD candidate at Bolton University-United Kingdom

- (MBA) Master in Logistics and Supply Chain Management, University of the West of Scotland, UK

- (PG DIP) Postgraduate Diploma in Logistics and Supply Chain Management, University of the West of Scotland, UK

- (B.Sc.) (HONS) Bachelor's with Honors degree in Business Information Technology, Manchester Metropolitan University, UK

- (Dip HE) Diploma in Higher Education in Information Technology, University of Paisley, UK 